\title{
TARIAN DAN TOPENG HUDOQ KALIMANTAN TIMUR: SUATU KAJIAN FILSAFAT SENI
}

\author{
Fauzia Latif \\ Design Interior Department, School of Design, BINUS University \\ Jln. KH. Syahdan No.9, Palmerah, Jakarta Barat 11480 \\ fauzia.latif@gmail.com
}

\begin{abstract}
Indonesia is a rich country of arts and cultures. Dayak culture is one example. Dayak community has distinctive and unique of culture, from art, social system, to belief system. Hudoq mask and dance are samples of the culture of East Kalimantan Dayak community which are not decorative shapes and motifs only, but also full of philosophical meaning and symbol of the community's faith. The results of this study are very important to record the progress of Dayak culture from ancient to present time, as well as to preserve the high values of Dayak community, as Indonesian people. This study can be used as materials in further Indonesian culture studying and served as examples to the upcoming art design world.
\end{abstract}

Keywords: art, East Kalimantan Dayak, Hudoq mask

\begin{abstract}
ABSTRAK
Indonesia adalah sebuah negeri dengan kekayaan seni dan budaya yang sangat beragam, salah satunya seni budaya masyarakat Dayak, Kalimantan Timur. Masyarakat Dayak memiliki seni dan budaya yang khas dan unik, dari seni, sistem kemasyarakatan hingga sistem kepercayaan. Tarian dan topeng Hudoq adalah salah satu bentuk kebudayaan masyarakat Dayak Kalimantan Timur yang bukan hanya sekadar hiasan bentuk dan motif saja, melainkan sarat dengan makna filosofis dan perlambang dari keyakinan masyarakatnya. Hasil dari penelitian ini sangat penting guna merekam perkembangan budaya masyarakat Dayak dari zaman dahulu hingga sekarang, sekaligus dapat mempertahankan nilai-nilai luhur masyarakat Dayak, sebagai masyarakat Indonesia seutuhnya. Kajian ini dapat dijadikan bahan dalam mempelajari seni budaya Indonesia selanjutnya dan dijadikan contoh dalam mendesain di dunia seni yang akan datang.
\end{abstract}

Kata kunci: seni, Dayak Kalimantan Timur, topeng Hudoq 


\section{PENDAHULUAN}

\section{Latar Belakang}

Kebudayaan merupakan suatu hal yang penting bagi kehidupan manusia. Dari kebudayaan dapat tercermin filosofi hidup dalam kehidupan bermasyarakat. Filosofi hidup ini adalah sebuah hal yang mendasar, dan merasuk di semua sendi kehidupan, seperti kesenian, perilaku, hubungan antarmanusia, ekonomi, dan hal lainnya. Masyarakat Dayak Kalimantan Timur merupakan perwakilan masyarakat Indonesia yang memiliki suatu sistem dan nilai-nilai luhur yang patut dikenal dan dipertahankan, karena merupakan ciri khas masyarakat Indonesia. Salah satu bentuk kebudayaan masyarakat Dayak Kalimantan Timur adalah tarian Hudoq dan topeng Hudoq, yang mencerminkan kehidupan bermasyarakat dengan konsep dualisme dan konsep tripartit-nya. Oleh karena itu, pembahasan kajian ini adalah untuk mengupas makna yang terdapat dalam tarian Hudoq dan Topeng Hudoq.

\section{Latar Belakang Geografis}

Kalimantan Timur berada pada garis katulistiwa 40 L.U. dan 20 L.S. Di sebelah barat dan utara berbatasan dengan Malaysia timur, di sebelah timur dengan selat Makasar, dan di sebelah selatan berbatasan dengan Kalimantan Selatan dan Kalimantan Tengah. Daerahnya terdiri dari daerah pantai, daerah pedalaman, dan dataran rendah. Sebagian besar wilayahnya berhutan lebat yang menghasilkan kayu dan hasil hutan lainnya seperti rotan, damar, dan lain-lain. Di samping kayu, Kalimantan Timur kaya pula dengan hasil tambang terutama miyak dan gas bumi.

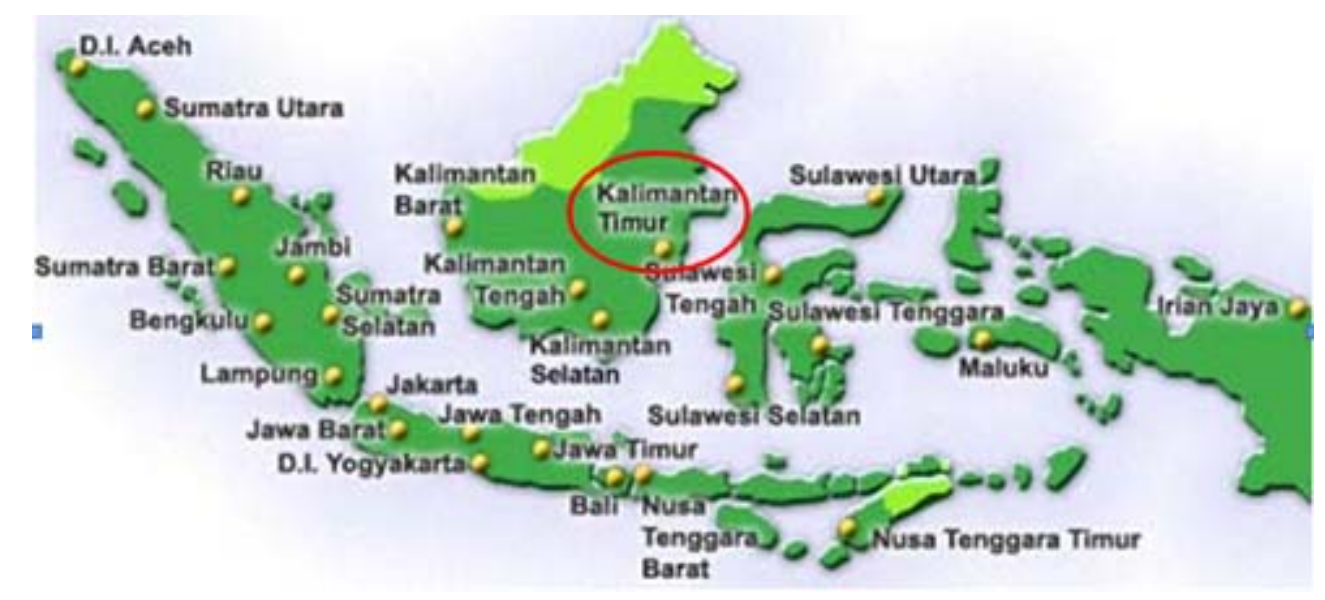

Gambar 1 Peta Negara Indonesia

Kalimantan Timur merupakan daratan raksasa dengan hutan lebat yang tak ada batasnya dan dibelah oleh sungai-sungai besar dan anak-anak sungai dari utara ke selatan, dan dari timur ke barat. Sungainya sangat banyak sekitar 161 batang sungai, dengan sungai Mahakam, Kandilo, Kayou, Segah, dan sungai Sesayap sebagai sungai terbesar. Karenanya sungai di provinsi ini mempunyai peranan penting di bidang komunikasi dan merupakan lalu lintas yang paling mudah untuk mengirim kayu. Lalu lintas jalan darat antarwilayah di Kalimantan Timur sudah ada, namun masih terbatas sekali.

Di daerah Kalimantan Timur, selain berdiam suku pendatang dari pulau Jawa, Sulawesi, dan pulau-pulau lain, sebagian besar didiami oleh penduduk asli yang terdiri dari suku Kutai, Dayak, dan Banjar. Suku Dayak yang mendiami pedalaman Kalimantan Timur terbagi dalam beberapa subsuku yakni Dayak Kenyah, Dayak Modang, Dayak Punang, dan Dayak Benuag. Di antara suku-suku Dayak 
tersebut, suku Kenyahlah yang banyak mempunyai kelompok. Suku Dayak Kenyah menurut adat terdiri dari empat kasta di bawah kekuasaan raja, yakni Kasta Paren yaitu kaum bangsawan, kasta Tetaaw juga kaum bangsawan, kasta Panyin yakni rakyat biasa, serta kasta Ulaq yaitu kasta kaum budak. Pada masa sekarang ini perbedaan kasta sudah tidak ada lagi, namun orang masih mengenal secara baik siapa yang masih keturunan bangsawan.

\section{Tinjauan Historis}

Kalimantan Timur mempunyai peninggalan sejarah yang cukup terkenal, yaitu Kutai dengan rajanya Mulawarman, satu masa dengan kerajaan Taruma Negara di Jawa Barat. Selain itu juga kerajaan-kerajaan lainnya seperti kerajaan Pasir Balengkung, Kerajaan Tabur, dan kerajaan Sambaliung di kabupaten Beran, kerajaan Tanjung Palas di kabupaten Bukungan dan kerajaan Hindu di Goa Kong Beng di kabupaten Kutai. Bekas-bekas kerajaan tersebut saat ini dijadikan museum Negara maupun daerah, kecuali bekas kerajaaan Tanjung Palas dan bekas kerajaan Hindu tua di Goa Kong Beng yang belum dipugar.

Penduduk asli Kalimantan Timur semula mempunyai kepercayaan animisme dan dinamisme. Kemudian dengan masuknya agama Hindu, mereka menganut ajaran Hindu. Kini banyak yang memeluk agama Islam maupun Kristen. Waulaupun begitu, kepercayaan mereka yang lama belum dapat mereka tinggalkan begitu saja. Hal ini terlihat pada upacara-upacara yang mereka lakukan sebagian besar masih berhubungan dengan sistem kepercayaan mereka yang lama. Masyarakat suku Dayak mengenal aneka ragam upacara, seperti tiwah, ijaruki, nyolat isan, dan sebagainya. Selain itu juga dikenal upacara adat penerimaan tamu, adat perkawinan, upacara adat pengobatan atau Bekan, dan upacara adat sesudah panen yang disebut ngungu tahun.

\section{Seni Sastra}

Di bidang seni, daerah Kalimantan Timur mempunyai corak ragam yang berbeda. Seni sastra suku Dayak selalu berhubungan dengan seni suara, karena riwayat atau cerita selalu disampaikan dengan lagu, yang disebut mausana.

\section{Seni Suara}

Seni suara lainnya adalah Mangandan yaitu lagu pujian untuk tamu, memanjung yakni seni suara pada upacara kematian, dinyanyikan dengan iringan gong. Kemudian seni suara mematih, yaitu lagu-lagu pujian yang dinyanyikan sesudah orang meninggal dunia, dan lain-lain.

\section{Seni Tari}

Seni tarian pun beraneka ragam, seperti tarian penyambut tamu, tari Kacut Julut, tari Gong. Ketiganya berasal dari Dayak Kenyah, tari Perang suku Dayak Bahau, tari Bangun dari Kutai, tari Pilin Tali suku Dayak Tunjung, tari Ganggereng atau tarian muda-mudi, dan lain-lain.

\section{Seni Lukis}

Di bidang seni lukis, dapat dilihat pada lukisan yang ada di perahu, dinding rumah serta bangunan lain, juga pada perisai. Umumnya, lukisan tersebut memakai waran-warna cerah yakni kuning, merah, biru, dan putih.

\section{Kerajinan}

Hasil kerajinan suku Dayak mempunyai nilai seni yang tinggi dengan warna yang sangat menarik, seperti kerajinan tenunan pakaian suku Dayak Benuag, anyaman manik-manik, anyaman rotan, macam-macam ukiran dari tulang binatang dan pahatan patung tradisional yang digunakan untuk keperluan upacara adat tradisioal, serta benda-benda kerajinan lainnya. Barang-barang kerajinan 
tersebut semula hanya dipergunakan bagi keperluan hidup sehari-hari, seperti mandau untuk menebang pohon, tombak untuk berburu, dan lain-lain. Kini barang-barang tersebut banyak diperjualbelikan di toko suvenir.

\section{Rumah Tradisional}

Seperti halnya suku Dayak di Kalimantan pada umumnya, suku Dayak di daerah Kalimantan Timur membuat rumah tradisional berbentuk rumah di atas tiang yang sangat panjang, karena untuk bertempat tinggal berpuluh-puluh keluarga. Selain menampilkan bangunan rumah tradisional rumah Lamin dari suku Dayak sebagai bangunan induknya, juga ditampilkan bangunan Kerangking yakni lumbung padi, dalam bahasa Dayak Tunjung. Semua bangunan yang ada di anjungan ini dilaksanakan di bawah arsitek Ir. Hartono Kadri dari Pekerjaan Umum Pusat.

Rumah Lamin adalah bentuk rumah di atas tiang yang sangat panjang, karena ditempati puluhan keluarga. Memang bentuk rumah seperti ini sudah merupakan bangunan rumah tradisional suku Dayak pada umumnya, hanya berbeda nama atau istilahya, serta beberapa variasi. Bahan seluruhnya dari kayu ulun yang berwarna hitam dan tahan lama. Karena rumah Lamin sangat panjang dan besar maka dapat menampung 200 orang. Biasanya dalam satu kampung hanya hanya terdapat tiga rumah Lamin, dan setiap kampung diketuai oleh seorang kepala adat atau kepala suku yang disebut Bakas Lewu atau Ungko Luwu.

Dengan perubahan dan kemajuan masyarakat sekarang ini, rumah Lamin sudah jarang ditemukan lagi. Mereka sudah banyak yang menempati rumah tersendiri seperti masyarakat perkotaan. Lamin yang masih ada, fungsinya sudah lain, yakni tidah berfungsi sebagai tempat tinggal melainkan untuk upacara-upacara keagamaan dan hiburan. Tempat tersebut digunakan untuk menyimpan alat-alat musik seperti gong, gendang, dan peralatan keperluan upacara adat tradisional. Sekitar bulan MaretApril bersamaan dengan musim kemarau dan musim panen, rumah Lamin di Kalimantan Timur ini kembali semarak dengan upacara adat yang diselenggarakan oleh masyarakat suku Dayak. Upacara yang dilaksanakan saat itu ada enam macam yakni upacara Pekian, Unding, Endang-Mirang, Melanggar Tuhing yang merupakan upacara ritual, dan upacara Bob Jengauw yakni upacara syukuran sukuran suku Dayak Modang di daerah kabupaten Kutai. Terkadang, masa-masa tersebut merupakan saat yang baik pula untuk melaksanakan upacara perkawinan ataupun upacara adat lainnya.

Rumah Lamin adalah rumah panjang yang bersambung-sambung, maka tata ruang di dalamnya merupakan rangkaian beberapa ruangan yang sama. Susunan ruangan hanya terdiri dari ruang yang merupakan las panjang, berfungsi sebagai tempat pertemuan, tempat melaksanakan upacara-upacara adat, serta tempat tidur bagi laki-laki dan pemuda serta tempat tidur tamu laki-laki. Di kanan kiri ruang depan terdapat bilik-bilik berderet yang merupakan tempat tidur keluarga dan anak gadis. Sedangkan di belakang bilik-bilik tidur adalah dapur untuk memasak dan tempat makan keluarga.

Di dalam rumah lamin terdapat ukiran-ukiran serta lukisan-lukisan sebagai hiasan, begitu pula di luarnya. Ukiran maupun lukisan tersebut mengandung makna dan simbol tertentu. Semua bentuk lukisan merupakan stilasi dengan motif geomatrik, motif pilin, dan motif kait-berkait membentuk ornamentasi yang abstrak dan sangat unik. Ukiran atau lukisan tersebut mengambarkan ular naga, burung enggang, cumi-cumi serta kedok dan kerangka manusia. Bagi orang Dayak, naga melambangkan kesaktian dan kekuatan serta kepahlawanan, burung enggang melambangkan ketinggian derajat manusia dan keluhuran budi. Burung enggang juga melambangkan kebangsawanan. Motif lukisan cumi-cumi melambangkan kerakyatan, sedangakan lukisan kedok atau topeng berangka manusia melambangkan kedamaian dari rakyat biasa. Ukiran atau lukisan naga dan burung enggang hanya terdapat pada rumah orang bangsawanan, sedangkan lukisan cumi-cumi dan kedok atau topeng terdapat pada rumah rakyat biasa. Warna yang dipakai adalah kuning, merah, biru, dan putih yang juga mengandung arti keagungan, keberanian, pengabdian, dan kesucian. 
Di depan lamin terdapat dua deret patung dari kayu ulin, berupa patung manusia dan hewan, sebagai penjaga lamin beserta seluruh penghuninya. Patung-patung ini ada yang di atas kepalanya terdapat binatang seperti kera, buaya, dan lain-lain. Menurut kepercayaan mereka, patung yang menghadap ke timur atau ke arah matahari terbit mempunyai kekuatan membantu mendatangkan rejeki dan kebaikan. Sedangkan patung yang menghadap ke selatan mempunyai fungsi sebagai penolak bala atau roh jahat yang akan mengganggu. Patung-patung ini dinamakan Sambang Lawing dari bahasa Dayak Tunjung. Di dekat patung terdapat tiang kayu yang tingggi disebut tiang Blontang, fungsinya untuk mengikatkan atau menambatkan binatang korban biasanya kerbau atau sapi, dalam suatu upacara adat. Binatang ini ditusuk-tusuk agar darahnya menitis ke tanah di sekeliling tiang Blontong, baru kemudian dipotong.

Di anjungan sebelah belakang terdapat bangunan kecil berupa sebuah peti berukir diberi tiang yang disebut Lungun. Lungun ini masih banyak ditemui di daerah Kalimantan Timur terutama di daerah pedalaman, merupakan kuburan bagi orang Dayak. Bila seorang meninggal, mayatnya dimasukkan ke peti yang disebut Tempela dan dibiarkan sampai membusuk. Tempela ini ditempatkan di tempat yang tinggi dan diberi saluran ke bawah untuk mengalirkan air yang keluar dari mayat tersebut. Bila mayat sudah kering dan tinggal tulang-tulang, lalu diambil dan ditaruh di dalam sebuah guci yang disebut antang, dan disimpan di dalam rumah sampai dapat melaksanakan upacara blontang. Sesudah melaksanakan upacara blontang dengan korban kerbau, tulang-tulang tadi dipindahkan ke lungun. Upacara blontang selain dilaksanakan dalam upacara korban penguburan juga dalam upacara perkawinan.

Kampung Telivaq (Matalibaq) terletak di tepi sungai Pariq (anak sungai Mahakam). Luas kawasan Telivaq 775.000 ha. Sebagian besar kawasan adatnya hutan belantara yang kaya kayu dan aneka hasil hutan, seperti satwa buruan, sarang burung, damar dan rotan yang dibudidayakan warga. Jumlah penduduk Telivaq sekitar $160 \mathrm{KK}$ (1.200 jiwa). Leluhur suku ini mendiami kawasan sungai Pariq sejak tahun 1815. Mata pencahariannya berladang, berkebun, dan memungut hasil hutan, yang dilaksanakan menurut tradisi adat. Hasil dari ladang, kebun dan memungut hasil hutan, merupakan sumber pendapatan ekonomi.

Sebelum kayu berharga, mata pencaharian warga Dayak Bahau di sepanjang sungai Mahakam dan anak-anak sungainya, adalah dari rotan, karet, hasil ladang dan hasil hutan non-kayu seperti madu, damar, gaharu, dan sarang walet. Kini sebagian besar warga Dayak sangat tergantung dengan hasil kayu. Padahal kayu makin hari makin habis akibat eksploitasi secara legal maupun ilegal. Di sepanjang sungai Mahakam berdiri puluhan sawmill dan ratusan ribu kubik kayu gelondongan. Namun, tidak ada satu pun sawmill dimiliki orang Dayak Bahau. Hutan-hutan di sepanjang sungai Mahakam, khususnya di wilayah kabupaten Kutai Barat, kini gundul akibat kayunya habis dan dilanda kebakaran hutan besar-besaran tahun 1998. Akibat hutan gundul, kini banjir menjadi bahaya yang sangat serius.

\section{Masyarakat Ladang}

Masyarakat Kalimantan Timur ini adalah masyarakat ladang. Sifat masyarakat ladang adalah masyarakat pengumpul makanan (pemburu dan peramu) dan masyarakat sawah. Dengan demikian, masyarakat ladang Kalimantan Timur ini bersifat dependen dan independen, konsumtif dan produktif. Prinsip kekeluargaannya erat (domestik), hubungan darah lebih penting dari hubungan lokalitas, serta pentingnya arti batas dan perantara.

Semua sifat masyarakat ladang ini dilandasi atas konsep dualisme keberadaan, yang terdiri atas dua kutub yang berbeda dan saling bertentangan. Kedua kutub tersebut dapat saling bertentangan, namun dapat pula saling melengkapi dan saling ketergantungan satu dengan yang lainnya dalam kehidupan. Perbedaan ini terlihat ketika adanya pemisah antara laki-laki dan perempuan, dunia atas dan dunia bawah yang kemudian melahirkan dunia tengah, seperti ayah dan ibu melahirkan anak. 
Persatuan antara dunia atas dan dunia bawah akan menghasilkan suatu kehidupan baru. Karena sifat masyarakat ini adalah segala sesuatu yang bertentangan harus diharmonikan, maka harus ada dunia tengah yang bersifat netral. Masyarakat primitif mengharapkan adanya dunia transendental. Oleh karena itu, terjadilah konsep tiga kesatuan atau tripartit keberadaan yang sempurna, yang merupakan hasil penyatuan dua kutub yang bertentangan yang kemudian saling melengkapi (komplementer).

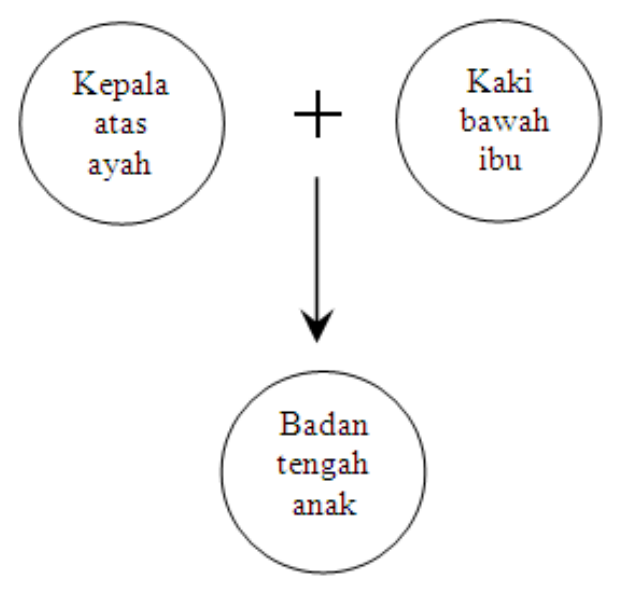

Gambar 2 Konsep Tiga Kesatuan atau Tripartit Timur.

Dasar tinjauan di atas menjadi acuan dalam menganalisis tari dan topeng Hudoq, Kalimantan

\section{Rumusan Masalah}

Tarian dan topeng Hudoq adalah salah satu bentuk kebudayaan masyarakat suku Dayak yang kurang dipublikasikan dan dianalisis. Salah satu penyebabnya adalah terpusatnya segala sesuatu di pulau Jawa, sehingga kurangnya perhatian di luar pulau Jawa, seperti Kalimantan. Tarian dan topeng Hudoq ini perlu lebih didalami karena dapat menguak filosofi hidup masayarakat Dayak yang sudah lama ada di Indonesia, dan generasi mendatang dapat mengenal tradisi dan filosofi hidup tradisional asli Indonesia melalui kesenian ini.

\section{Tujuan Penelitian}

Tujuan dari penelitian ini adalah, melalui kajian tarian Hudoq dan topeng Hudoq, untuk merekam perkembangan budaya masyarakat Dayak dari zaman dulu hingga sekarang, sekaligus mempertahankan nilai-nilai luhur masyarakat Dayak sebagai masyarakat Indonesia seutuhnya. Kajian ini dapat dijadikan bahan dalam mempelajari seni budaya Indonesia selanjutnya dan dijadikan contoh mendesain didalam dunia seni yang akan datang.

\section{METODE PENELITIAN}

Metode penelitian yang akan digunakan adalah dengan melakukan studi terhadap tarian Hudoq, dan mempelajari bentuk dan lukisan topeng Hudoq Kalimanatan Timur, untuk mengetahui pentingnya tari dan topeng Hudoq sebagai bagian dari seni dan budaya masyarakat Dayak, serta mengetahui sejauh mana pengaruh konsep dualisme dan tripartit pada topeng Hudoq tersebut terhadap kehidupan di dalam masyarakat Dayak Kalimantan Timur. 


\section{HASIL DAN PEMBAHASAN}

\section{Analisis Tarian Hudoq Bahau}

Konsep tripartit diterapkan melalui penyatuan antara masyarakat dan pemimpin yang menghasilkan sebuah adat. Adat istiadat ini dikembangkan oleh masyarakat Dayak, dan salah satunya berupa tarian mistis. Kalangan orang Dayak Bahau, Kalimantan Timur memercayai adanya kekuatan mistis yang melingkupinya, yang kepercayaan tersebut dimanifestasikan lewat tari-tarian. Tarian yang dimaksudkan adalah "Tarian Hudoq" yang merupakan ritual terbesar dan terutama dalam masyarakat Dayak Bahau. Tarian ini, dalam pementasannya menggunakan topeng sebagai alat untuk menghadirkan suasana mistis. Tujuan pelaksanaan upacara dan tarian Hudoq ini adalah untuk menciptakan keselarasan dengan lingkungan alam, terutama sekali agar memperoleh jaminan keberhasilan panen di ladang dengan dibantu oleh dewa. Dengan demikian, tarian ini di samping sebagai tarian mistis juga sebagai tarian animisme (pemujaan pada dewa-dewa). Eksistensi Hudoq tidak bisa dipisahkan dari tradisi berladang. Jika orang Bahau tidak berladang lagi, Hudoq pun akan hilang. Jika pun masih ada, ia tidak mempunyai spirit lagi, tinggallah sebuah seni yang tanpa makna. Kekhawatiran hilangnya hudoq makin hari makin dirasakan generasi tua Dayak Bahau, karena semakin kecilnya lahan untuk berladang akibat masuknya perusahaan hutan yang menguasai, serta orang luar yang masuk untuk mengeksploitasi kayu.
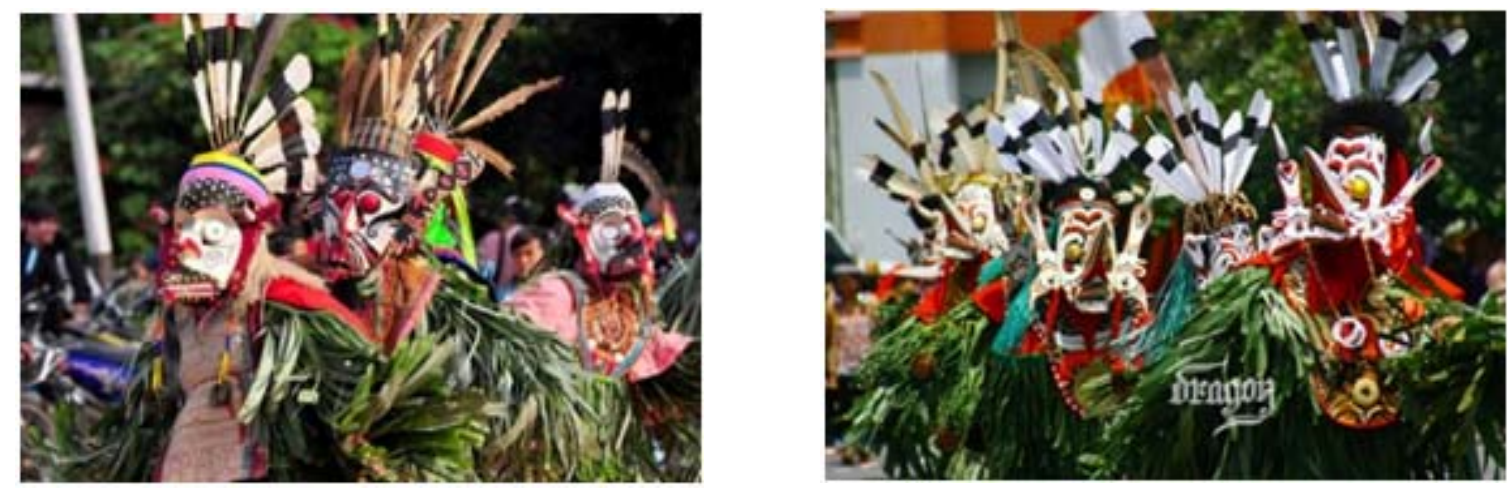

Gambar 3 Tarian Hudoq Bahau

Tarian Hudoq seperti digambarkan secara ringkas tersebut, hanyalah merupakan salah satu contoh kecil masih dipertahankan dan dilestarikannya tarian tersebut yang mengandung makna tersendiri yang sangat berkaitan dengan kosmologi orang Dayak Bahau. Adapun kehadiran lain tarian Hudoq dalam kehidupan sosial-budaya orang Dayak Bahau adalah dalam acara resmi atau peringatan hari besar, pesta adat dan bahkan dalam pentas-pentas seni lainnya, baik dalam skala lokal, nasional, maupun skala internasional.

Hudoq orang Dayak Bahau di aliran sungai Mahakam, dilaksanakan ketika musim menanam padi di ladang, sekitar bulan Oktober-November. Ritual Hudoq dimaksudkan untuk mengantar jiwa padi dari rumah ke ladang. Upacara adat setahun sekali ini harus dilaksanakan dengan semeriah mungkin agar roh padi senang tinggal di ladang. 


\section{Analisis Topeng Hudoq}

Kata Hudoq dalam bahasa Dayak Bahau berarti topeng. Hudoq masyarakat Dayak Bahau di aliran sungai Mahakam (Mekam dalam bahasa Dayak Bahau) sama di semua kampung. Tarian Hudoq, penarinya menggunakan topeng yang disebut Hudoq.

Pada masyarakat Dayak Bahau di sungai Pariq, Hudoq dilaksanakan menjelang panen padi di ladang selama 7 atau 10 hari, setiap hari berbeda Hudoq-nya. Urutannya sebagai berikut: Hudoq Suh Doh, Hudoq Lake, Hudoq Tajung Long Belan, Hudoq Tajung Lavung Kirap, Hudoq Suh Doh, Hudoq Kuhaw Habung Ajat Inaang Pa’ Pa'an, Hudoq Hakaai, Hudoq Habung Ajat, Hudoq Kalang, dan Hudoq Kuhaw Inaang Pa’ Paan.

Puncak Hudoq pada hari terakhir. Pada hari terakhir, semua Hudoq yang pernah tampil, beraksi lagi. Nama-nama Hudoq tersebut membedakan ritual yang dilakukan serta topeng dan aksesori yang dipakai. Pada Hudoq Suh Doh misalnya, sebelum ritual Hudoq dilangsungkan, pewaris Hudoq memanen padi di ladang sekitar $1 \mathrm{~kg}$ dan disimpan dalam ruas bambu. Padi inilah yang ditarikan dan dibuat ritualnya, kemudian pada akhir ritual padi tersebut dibagikan ke semua orang yang hadir. Padi inilah yang kemudian dicampur dengan benih untuk ditanam di ladang tahun berikutnya. Meski agak berbeda masing-masing Hudoq, umumnya bahan utama ritual Hudoq adalah topeng dari kayu, daun pisang dan akar untuk pengikatnya. Topeng untuk menutupi muka dan daun pisang yang dibelah-belah sehingga membentuk rumbai-rumbai diikatkan hingga menutupi kaki, paha, pinggang, tang han dan bahu. Setiap kali berhudoq, daun pisang yang dipakai harus baru. Daun pisang bekas Hudoq tidak boleh dibakar, tetapi ditumpuk dan dibiarkan busuk jadi pupuk.

Pemain Hudoq umumnya harus orang yang bermukim di kampong, tempat Hudoq dilaksanakan. Satu-satunya Hudoq yang bisa dimainkan oleh tamu yang datang atau Hudoq dari kampung lain adalah Hudoq Hakaai. Ketika Hudoq sedang beraksi, ada juga duplikat hama padi di ladang, seperti kera, tikus, babi, rusa, dan burung pipit yang tampil. Hudoq hama ini juga berfungsi sebagai penghibur.

Selain Hudoq hama, pada saat bersamaan ada Hudoq perempuan. Hudoq perempuan ini ada yang bertopeng dan ada yang tidak, juga ada yang badannya dibungkus dan ada yang tidak dibungkus dengan rumbai-rumbai daun pisang. Muka dan badan diukir dengan arang pewarna lainnya dan membawa perlengkapan hidup sehari-hari seperti bakul, nyiru, pengambin. Hudoq perempuan ini melakukan atraksi sebagai simbol tradisi dan adat masyarakat Bahau. Misalnya bagaimana orang Bahau berpacaran dan memelihara bayi, bagaimana orang menangkap ikan dan binatang buruan.

Yang menarik pada Hudoq dari desa Telivaq yaitu pemegang adat tertinggi Hudoq adalah perempuan. Karena menurut Song Devung, 80 tahun, pemegang adat Hudoq, yang pertama kali menemukan adat Hudoq dan menjadi raja Hudoq adalah perempuan. Sehingga sampai kini yang memimpin ritual Hudoq adalah perempuan. Ini sekaligus cermin dari prinsip dualisme yang memisahkan antara laki-laki dengan perempuan pada orang Dayak Bahau.

Terdapat tiga jenis topeng Hudoq yang digunakan, yaitu: Hudoq nyam'ake, yang melambangkan pemuda yang gagah berani yang bertugas sebagai prajurit; Hudoq urung pakau, dikenakan oleh orang yang dituakan di kampung, yaitu pemimpin kelas menengah yang memberikan komando kepada prajurit saat perang; Hudoq ba'kap, yaitu dikenakan oleh pemimpin adat yang sekaligus mengepalai tarian Hudoq.

Ketiga jenis topeng Hudoq diatas memiliki kesamaan bentuk namun memiliki fungsi atau tugas yang berbeda-beda, seperti gambar berikut: 


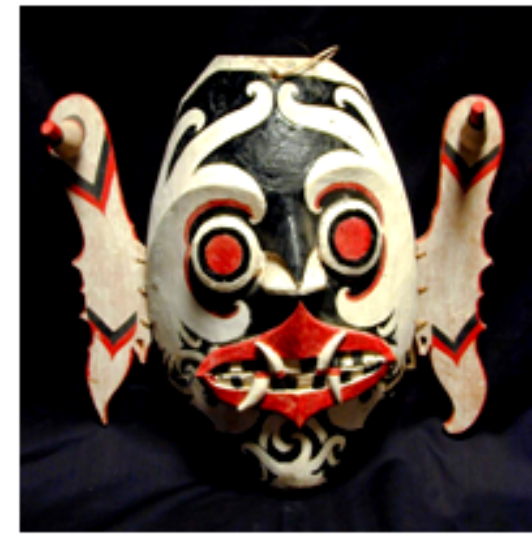

Gambar 4 Topeng Hudoq Nyam'ake

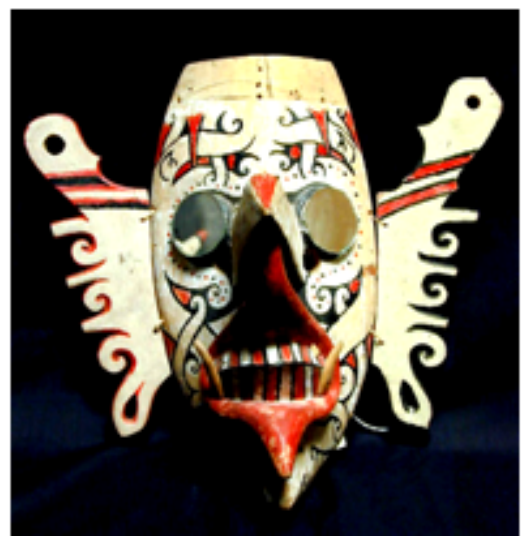

Gambar 5 Topeng Hudoq Urung Pakau

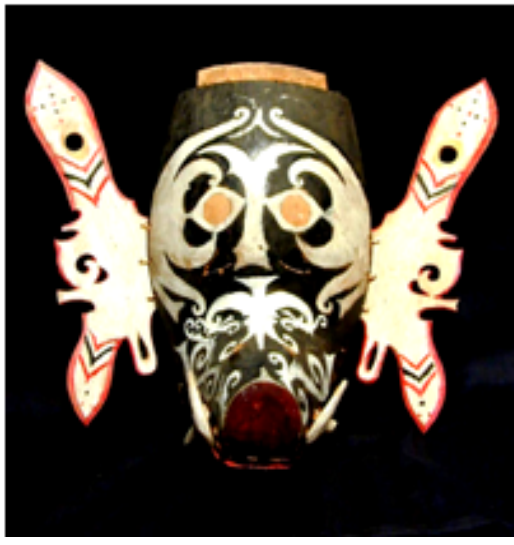

Gambar 6 Topeng Hudoq Urung Pakau

Menurut kepercayaan orang Bahau, yang membawa padi dari kayangan adalah binatangbinatang, seperti rusa, babi, kera, burung-burung. Karena itulah topeng-topeng hudoq dibuat seperti binatang-binatang itu. Warna dari topeng tersebut didominasi oleh warna putih yang melambangkan pengabdian dan kesucian, hal ini mewakili dari tarian Hudoq yang sifatnya suci serta merupakan bentuk pengabdian dari masyarakat Dayak terhadap Dewanya. Warna yang kedua adalah merah, yang mewakili masyarakat Dayak yang berani dan pantang menyerah dalam mencapai keberhasilan panen mereka di ladang.

Berikut ini adalah analisis konsep dualisme dengan cara pembagian vertikal pada topeng Hudoq:
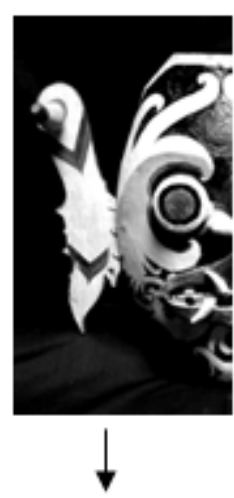

Laki-laki

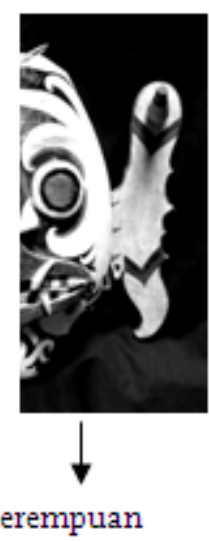

Perempuan

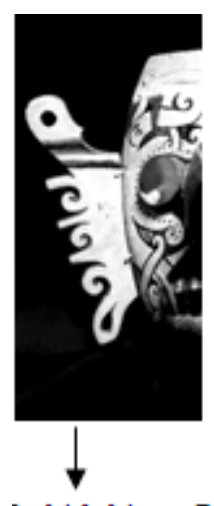

Laki-laki

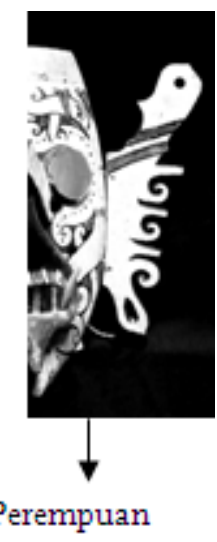

Gambar 7 Analisis Unsur Dualisme

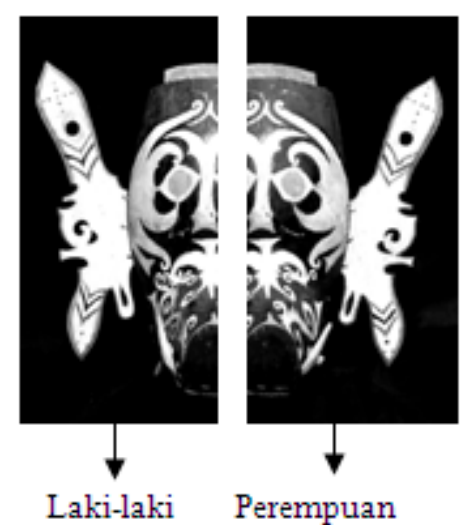

Laki-laki

Perempuan

Lukisan atau hiasan yang terdapat pada topeng Hudoq di atas, apabila kita membuat garis di tengah topeng secara vertikal, mengakibatkan pembagian yang sama namun saling berlawanan. Hal ini melambangkan adanya dualisme yang mewakili laki-laki dan perempuan yang diterapkan pada suku tersebut. Hudoq:

Berikut ini adalah analisis konsep tripartit, dengan cara pembagian horizontal pada topeng 


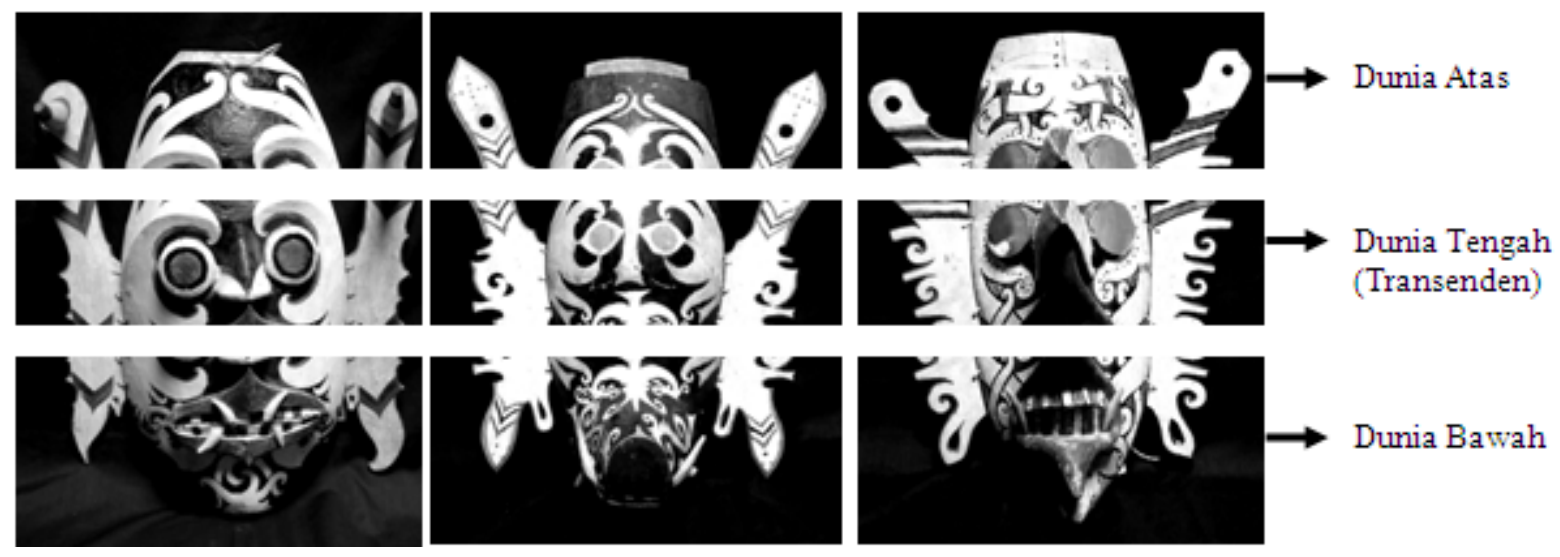

Gambar 8 Analisis Unsur Tripartit

Pada ketiga topeng Hudoq ini apabila dibagi tiga bagian secara horizontal, bentuk dan lukisan pada topeng ini melambangkan antara dunia atas, dunia tengah, dan dunia bawah. Dunia bawah dengan bentuk dan lukisan pada topeng yang mengarah ke bawah mendekati bumi, yang terdapat hasil panen serta hubungan sosial terhadap sesama, mewakili manusia. Dunia atas dengan bentuk dan lukisan pada topeng yang mengarah ke atas, dan dengan bentuk yang menjunjung tinggi dan agung, mewakili Sang Pencipta atau Dewa-nya. Dunia tengah dengan bentuk dan lukisan pada topeng yang mengarah ke samping mewakili suatu hal transenden dan berjiwa mistik yang berfungsi sebagai zona penghubung antara kedua dunia. Hal mistik ini diwujudkan melalui tari-tarian yang merupakan media perwujudan rasa syukur terhadap hasil panen yang diberikan oleh Dewa kepada masyarakat Dayak tersebut.

\section{SIMPULAN}

Masyarakat Kalimantan Timur adalah masyarakat ladang. Sifat masyarakat suku Dayak mementingkan batas-batas di dalam masyarakatnya yang terbukti dari tingkatan kasta yang ada, dan hubungan kekeluargaan di dalam kasta tersebut sangat erat. Sifat masyarakat ladang ini memiliki konsep dualisme, yaitu memisahkan antara dua kutub yang berlawanan. Kemudian disatukan dengan unsur yang merupakan gabungan dari kedua kutub tersebut sehingga menghasilkan sesuatu yang baru, yang bersifat transenden dan sakral, dunia tengah yang sifatnya baru, berbeda dan belum dikenal. Dunia tengah ini berhubungan dengan hal-hal yang mengandung nilai spriritual. Oleh karena itu berkembanglah suatu kepercayaan yang salah satunya berupa tarian mistis. Tarian ini berhubungan erat dengan kebiasaan mereka yang merupakan masyarakat lading, yaitu untuk mendapatkan kesuburan atas tanah yang digarap mereka dan mengharapkan hujan yang turun tiada henti. Tarian ini disebut tarian Hudoq yang merupakan tarian topeng.

Konsep dualisme terlihat dari pemisahan antara wanita dan laki-laki dalam menarikan tarian Hudoq. Kemudian konsep ini juga diterapkan pada topeng tersebut, yang berupa pembagian secara vertikal antara dua bagian yang sama namun saling berlawanan. Kemudian diterapkan pula konsep tripartit pada topeng tersebut, yang berupa pembagian secara horizontal dan membagi menjadi tiga bagian yaitu dunia atas, dunia tengah dan dunia bawah. Hal tersebut merupakan perwujudan dari masyarakat yang berhubungan dengan Tuhan atau Dewa mereka melalui suatu hal yang transenden dan berjiwa mistik.

Konsep dualisme semata-mata ingin menghubungkan antara dua dunia yang berbeda, yaitu antara manusia dan Sang Pencipta. Dengan adanya konsep ini maka masyarakat Dayak Kalimantan Timur merupakan masyarakat yang menjunjung tinggi segala bentuk komunikasi, baik sesama 
manusia dengan bahasanya, maupun antara manusia dengan Penciptanya dengan unsur-unsur trasenden sebagai perwakilan dari bentuk komunikasi, hal tersebut menunjang perkembangan budaya masyarakat Kalimantan Timur ini.

Hasil dari penelitian ini sangat penting guna merekam perkembangan budaya masyarakat Dayak Kalimantan Timur dari zaman dahulu hingga sekarang, sekaligus dapat mempertahankan nilainilai luhur yang terdapat pada masyarakat Dayak Kalimantan sebagai masyarakat Indonesia seutuhnya. Kajian topeng Hudoq, merupakan perwujudan seni budaya Indonesia yang mengandung makna-makna filosofis yang mendalam. Hal ini dapat dijadikan kajian dalam mempelajari seni budaya Indonesia selanjutnya dan dijadikan contoh dalam mendesain pada dunia seni mendatang.

\section{DAFTAR PUSTAKA}

Cerita Rakyat Nusantara. (19 Oktober 2010). Cerita Rakyat Sumber Inspirasi Berbagai Tari Topeng Nusantara. Diambil dari http://ceritarakyatnusantara.com/id/news/101-Cerita-Rakyat-SumberInspirasi-Berbagai-Tari-Topeng-Nusantara\#

Koentjaraningrat. (2002). Manusia dan Kebudayaan di Indonesia. Jakarta.

MooChenk. (April 2009). Tari Hudoq dari Kalimantan Timur. Diambil dari http://dunialainlaindunia.blogspot.com/2009/04/tari-hudoq-dari-kalimantan-timur.html.

Wikipedia. (2004). Kalimantan Timur. Diambil dari http://id.wikipedia.org/wiki/Kalimantan_Timur. 